\title{
Prospects for use of new sources of dietary fibers in the technology of flour confectionery products
}

\author{
Olga Samokhvalova ${ }^{1 *}$, Svitlana Oliinyk $^{1}$, Kateryna Kasabova ${ }^{1}$, Galyna Stepankova ${ }^{1}$, and Olena Bolkhovitina ${ }^{1}$ \\ ${ }^{1}$ Department of Bakery Confectionary, Pasta and Food Concentrates Technology, Kharkiv State University of Food Technology and \\ Trade, Kharkiv, Ukraine
}

\begin{abstract}
The rationale for enrichment of flour confectionery products with dietary fibers was shown and the use of plant raw materials by-products, namely wheat germ oil cake and beet fibers as the sources of such dietary fibers, was justified. The content of nutrients, the quantitative and qualitative composition of dietary fibers as well as the granulometric composition were determined in the studied additives. The functional and technological properties of additives such as water absorbing ability depending on water temperature and duration of swelling and fat binding capability were studied.
\end{abstract}

\section{Introduction}

Flour confectionery products are one of the most popular food products in many countries around the world due to their flavour, attractive appearance, and good digestibility. The range of flour confectionery products is highly diverse, but most of them are characterized by the high caloric content due to the significant content of fats and easily digested carbohydrates as well as by the low content of physiological and functional ingredients, including dietary fibers [1].

As is well known, dietary fibers bear a set of vital functions in human body, showing sorption and prebiotic properties, participating in digestive processes, preventing obesity, cardiovascular, cancer and other diseases [2-5]. For this purpose, modification of the chemical composition of flour confectionery products in order to increase the content of dietary fibers therein is a relevant and timely objective. What is important to notice is that dietary fibers, on the one hand, play an important physiological role, and on the other hand, they show the technological properties of food additives that affect the structure and physical and chemical characteristics of food products owing to their origin and structure features [6].

Dietary fiber is a complex of polysaccharides (cellulose, hemicellulose, pectic substances) and lignin, which forms the cell walls of plants [2,7]. Dietary fibers are polymeric compounds varying in the composition and structure of monomers, their sequence in the polymer chain, position of glycoside bonds, molecular mass and degree of polymerization as well as in space structure and packing density. It is the molecular structure and composition that determine the differences in such physical and chemical properties as water solubility, solution viscosity, water-holding capacity, thickening and gelling property, sorption and ion-binding properties.

*Corresponding author: sam55ov@gmail.com
Many polysaccharides related to dietary fibers are traditionally used in food technologies as dispersion thickening agents and stabilizers [8]. In this case, their dosage as technological components is low (0.01-1.5\%). However, the enrichment of a food product with dietary fibers involves their inclusion in the amount of at least 3 $6 \mathrm{~g}$ per $100 \mathrm{~g}$ of the finished product, which is associated with possible change in its quality. In the process of development of the flour confectionery products technology with the use of new sources of dietary fibers $[9,10]$, it is necessary to clarify their chemical composition as well as study the functional and technological properties making it possible to predict the course of the technological process.

Plant raw material by-products, namely wheat germ oil cake (hereinafter referred to as the oil cake) and beet fibers that are produced in Ukraine were used as a source of dietary fibers in these studies. The oil cake along with dietary fibers contains a significant amount of protein, vitamins and minerals. Two types of beet fibers unclarified (UBF) and clarified (CBF), the technology of which is distinguished by availability of an additional stage of hydrogen peroxide treatment during their production, were studied. They contain a significant amount of dietary fibers and minerals.

The study purpose is to determine the chemical composition of beet fibers and oil cake and the grain particle size of their polysaccharide mixtures as well as the functional and technological properties of the studied additives.

\section{Experimental}

The protein content was determined by the modified Kjeldahl method, the content of free carbohydrates, water-soluble polysaccharides and hemicellulose was determined according to the modified Dreywood method [11], the quantitative determination of cellulose was 
carried out by the nitrogen-alcohol method (Kurschner method), determination of pectic substances - by the calcium-pectate method [12] and lignin - by the method of Willstatter and Zechmeister [13].

The granulometric composition of beet fibers and oil cake was determined by the microscopical method with plotting the differential function of particle size distribution [14].

In order to determine the fat binding capability (FBC), a portion of the studied additives with the weight of $5 \mathrm{~g}$ was taken and placed in a measured spinner flask, and 30 $\mathrm{ml}$ of refined winterized sunflower oil were added. The mixture was stirred for $1 \mathrm{~min}$ at an electronic stirrer spin rate of $1,000 \mathrm{rpm}$, infused for $30 \mathrm{~min}$, and then centrifuged for $15 \mathrm{~min}$ at a centrifuge spin rate of $4,000 \mathrm{rpm}$. The nonpick-up oil was drained off; the flask was left in an inclined position for $10 \mathrm{~min}$ in order to remove remaining oil.

After that, the flasks were weighed and the FBC factor was calculated using the formula, $\%$ :

$$
F B C=\frac{a-b}{c} \times 100,
$$

where $a$ - weight of the flask with the portion and associated oil, $\mathrm{g} ; b$ - weight of the flask with the portion, $\mathrm{g} ; c$-weight of the portion, $\mathrm{g}$.

The factor of water absorbing ability (WAA) was determined in the same manner as the FBC procedure using distilled water instead of oil.

Since the particle fineness of the critical raw materials of flour products and vegetable enriching additives significantly affects the process of dough formation and the structural and mechanical properties of dough, it was deemed advisable to determine the granulometric composition of the studied additives (Fig. 1).

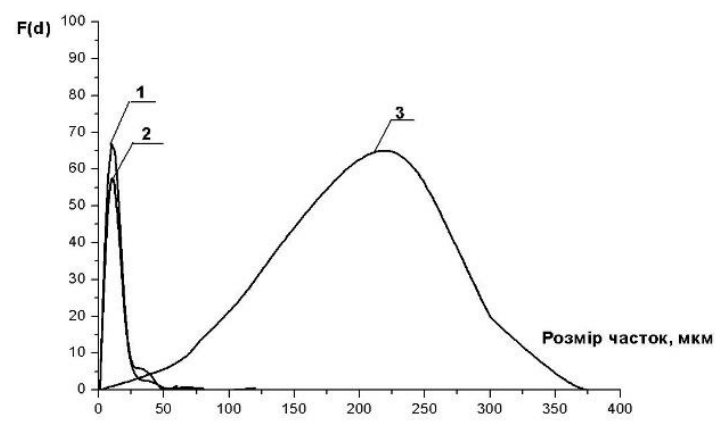

Fig. 1. Dependence of the Differential Distribution Function F(d) on the Particle Size of the Studied Additives: 1 Unclarified Beet Fibers; 2 - Clarified Beet Fibers; 3 - Wheat Germ Oil Cake.

Table 1 shows the results of determination of nutrients and dietary fibers in the studied additives.

The dependences of water absorbing ability of the $\mathrm{UBF}, \mathrm{CBF}$ and wheat germ oil cake on water temperature and duration of swelling are shown in Fig. 2, 3.

The WAA of the studied additives was determined in the temperature range of $20 \ldots 100^{\circ} \mathrm{C}$ that is inherent in the technological processes of preparation of flour confectionery products $\left(20^{\circ} \mathrm{C}-\right.$ dough kneading temperature, $40 \ldots 60^{\circ} \mathrm{C}$ and $80 \ldots 100^{\circ} \mathrm{C}-$ dough piece temperature respectively at the beginning and at the end of baking process).

Table 1. Nutrient and dietary fiber content of studied additives.

\begin{tabular}{|c|c|c|c|}
\hline \multirow{2}{*}{ Substance } & \multicolumn{3}{|c|}{$\begin{array}{c}\text { Weight fraction of a substance in the } \\
\text { studied additives, \% }\end{array}$} \\
\cline { 2 - 4 } & UBF & CBF & $\begin{array}{c}\text { Wheat germ } \\
\text { oil cake }\end{array}$ \\
\hline Protein & $7.00 \pm 0.20$ & $9.00 \pm 0.30$ & $37.00 \pm 1.00$ \\
\hline Carbonhydrates & $81.70 \pm 3.60$ & $77.30 \pm 2.70$ & $44.80 \pm 1.60$ \\
\hline $\begin{array}{c}\text { incl. } \\
\text { monosaccharides } \\
\text { and } \\
\text { disaccharides }\end{array}$ & $1.10 \pm 0.10$ & $1.30 \pm 0.11$ & $22.00 \pm 0.40$ \\
\hline Dietary fibers: & $80.60 \pm 3.50$ & $76.00 \pm 2.60$ & $22.80 \pm 1.20$ \\
\hline soluble & $20.70 \pm 0.50$ & $21.00 \pm 0.50$ & $7.80 \pm 0.05$ \\
\hline insoluble & $59.90 \pm 3.50$ & $55.00 \pm 2.00$ & $15.00 \pm 1.00$ \\
\hline incl. cellulose & $25.90 \pm 0.44$ & $24.80 \pm 0.20$ & $6.20 \pm 0.40$ \\
\hline hemicellulose & $23.20 \pm 1.40$ & $21.30 \pm 1.10$ & $15.30 \pm 0.50$ \\
\hline pectic substances & $22.20 \pm 1.50$ & $21.90 \pm 1.20$ & $1.30 \pm 0.05$ \\
\hline lignin & $9.30 \pm 0.16$ & $8.00 \pm 0.12$ & $1.00 \pm 0.10$ \\
\hline
\end{tabular}

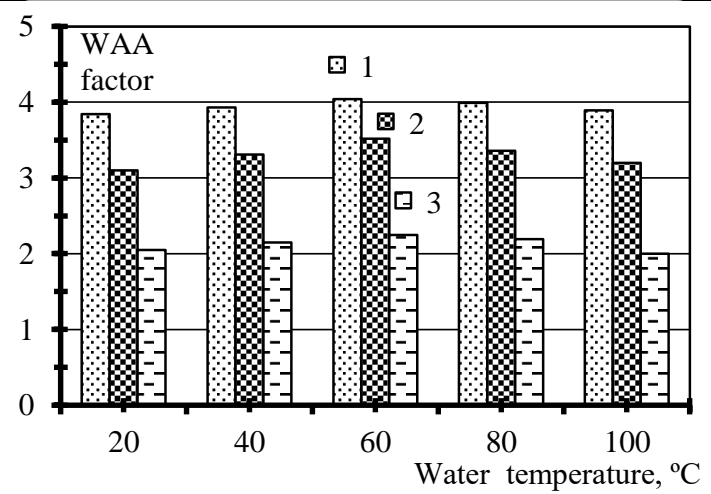

Fig. 2. Dependence of the Factor of Water Absorbing Ability (WAA) of the Additives on Water Temperature: 1 Unclarified Beet Fibers; 2 - Clarified Beet Fibers; 3 - Wheat Germ Oil Cake.

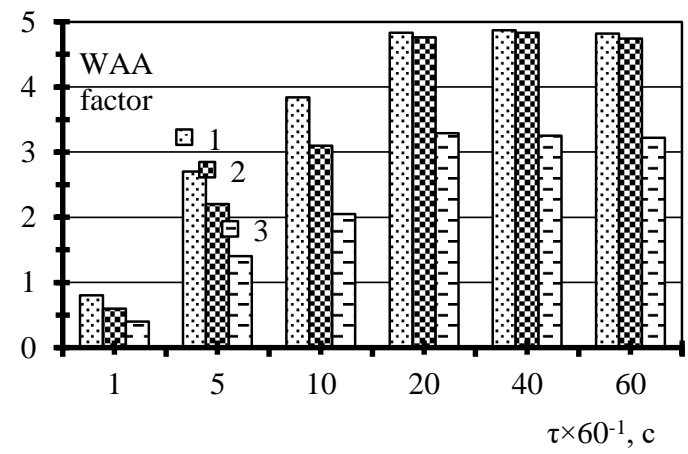

Fig. 3. Dependence of the Factor of Water Absorbing Ability (WAA) of the Additives on Duration of Swelling: 1 Unclarified Beet Fibers; 2 - Clarified Beet Fibers; 3 - Wheat Germ Oil Cake.

In order to determine the time required for the maximum swelling of the additives, the WAA factors according to swelling within $1 . .60 \mathrm{~min}$ (Fig. 3) were determined. The additives were hydrated at the temperature of $20^{\circ} \mathrm{C}$. 
Since the raw materials containing fat are used for production of flour confectionery products, we have studied the fat binding capability (Table 2).

Table 2. Fat binding capability (FBC) of beet fibers and oil cake.

\begin{tabular}{|c|c|c|l|}
\hline Studied additives & $\begin{array}{c}\text { Unclarified } \\
\text { beet fibers }\end{array}$ & $\begin{array}{c}\text { Clarified } \\
\text { beet fibers }\end{array}$ & Oil cake \\
\hline $\begin{array}{c}\text { Water absorbing } \\
\text { ability factor }\end{array}$ & $1.81 \pm 0.08$ & $1.41 \pm 0.07$ & $1.11 \pm 0.05$ \\
\hline
\end{tabular}

\section{Results and discussion}

As shown by the data given in Table 1 , the composition of beet fibers contains $7.0 \ldots 9.0 \%$ of protein, and the composition of oil cake contains the significantly larger amount of protein $(37.0 \%)$. All additives are notable for high content of carbohydrates, which are represented by a mixture of polysaccharides belonging to dietary fibers, by almost $98.0 \%$ for beet fibers and $60.0 \%$ for oil cake. It should be emphasized that the grain particle size of DF of all additives is represented by cellulose, hemicellulose, pectic substances and lignin, but differs significantly in their quantitative content. Dietary fibers of the oil cake are represented by the hemicelluloses and cellulose complex, and the beet fibers also contain a significant amount of pectic substances. In our opinion, the amount of all polysaccharides in the clarified beet fibers is slightly lower than in unclarified ones due to the difference in their production process: during the clarification stage, some of the polysaccharides are lost and changed into soluble forms. According to the differential distribution function shown in Fig. 1, which characterizes the particle fineness of the additive samples, it can be seen that a significant amount of UBF (67\%) and CBF (57\%) particles have a size of $10 \ldots 20 \mu \mathrm{m}$. Fractions of particles with a size of $20 . .30 \mu \mathrm{m}$ are contained in $\mathrm{CBF}$ in the amount of $21 \%$, and in UBF in the amount of $9 \%$. The maximum size of the insignificant amount of particles of beet fibers does not exceed $70 \mu \mathrm{m}$.

Summing the above, it is worth noting that beet fibers and oil cake differ in chemical composition, quantitative and qualitative composition of DF and particle fineness. This suggests that they have totally different effects on the colloid and physicochemical processes during dough kneading and flour confectionery products baking. Therefore, it was considered necessary to determine such important (in that respect) functional and technological properties of these additives, such as water absorbing ability (WAA) and fat binding capability (FBC).

The WAA factors of the additives depending on the water temperature (Fig. 2) indicate that the WAA factor for $\mathrm{UBF}$ at the temperature of $20^{\circ} \mathrm{C}$ is 3.8 , for $\mathrm{CBF}-3.1$, for oil cake -2.0 . The lower water absorbing ability of CBF compared to UBF is due to the fact that some part of protopectin is converted into water-soluble pectin during clarification. The lower WAA factor of the oil cake compared to beet fibers is due to the lower amount of hemicellulose and pectic substances. As the water temperature rises, the WAA factor changes slightly. Moreover, there is a general trend towards some increase in this indicator when temperature increases to $60^{\circ} \mathrm{C}$ and decrease in this indicator upon further heating. This may be related to the beginning of the protein denaturation process, which leads to a decrease in their hydration capacity. This dependence is especially noticeable in case of oil cake that contains more proteins in comparison with beet fibers. The obtained data indicate that the temperature of $20^{\circ} \mathrm{C}$, at which (mainly) kneading of dough for flour confectionery products is carried out, is sufficient for their swelling.

Fig. 3 shows that in the first minute of swelling, the WAA factor is 0.8 for UBF, 0.6 for CBF, and 0.4 for oil cake. The extension of the duration of swelling from 1 to 20 min has a significant impact on the WAA factor, which increases by 6 and 7 times for UBF and CBF, respectively, and by 8 times for oil cake compared with the indicators obtained within $1 \mathrm{~min}$. When tempering the additives for 20...40 minutes, the WAA factor increases slightly. After the expiration of 40 minutes, the WAA factor decreases which may be due to the transition of high methylated pectin into a state of unlimited swelling. Thus, the most intense swelling of the particles of the studied additives occurs during the first 10 minutes.

In terms of fat binding capability, the unclarified beet fibers outmatch the clarified ones and oil cake. The availability of this capability in additives is a prerequisite for better fat binding during the structure formation of the dough for flour confectionery products.

\section{Conclusion}

Therefore, the chemical and granulometric composition, functional and technological properties of beet fibers and wheat germ oil cake were determined. It was found that they are high in dietary fibers, and oil cake is additionally high in protein. It is characteristic that dietary fibers of wheat germ oil cake are mainly represented by the hemicelluloses and cellulose complex, and beet fibers also contain a significant amount of pectic substances. The additives have a different granulometric composition according to which beet fibers can be classified as finely dispersed, and oil cake can be classified as coarsely dispersed powder products. They are characterized by significant water absorbing ability and fat binding capability, which makes it possible not only to predict an increase in the nutrition value of finished products, but also their great effect on the dough formation processes.

\section{References}

1. I. Matseichik, S. Korpacheva, V. Muntyan, Bull. Buryat State Acad. Agric. named after V.R. Philippov, 50, 103-108 (2018)

2. Ya. O. Li, A. R Komarek, Food Qual. Saf., 1, 47-59 (2017)

3. I. Bronovets, MNT, 10, 46-48 (2015)

4. A. Ghada, Nutrients, 11 (2019)

5. W. Han, S. Ma, L. Li, X.-X. Wang, X.-L. Zheng, J. Chem, 2017 (2017) 
6. L. Ipatova, A. Kochetkova, O. Shubina, T. Dukhu, M. Levacheva, Food Ind., 1 (2004)

7. S. Merenkova, O. Zinina, M. Stuart, E. Okuskhanova, N. Androsova, Hum. Sport Med., 20, 106-113 (2020)

8. N. Tipsina, N. Prisukhina, Bull. KrasGAU, 9 , 166-171 (2009)

9. M. Mironov, A. Kudrina, Innov. Mach. Technol., 4, 36-40 (2017)

10. M. Hasan, [et al.], ASNH, 3, 181-183, 2019
11. D. Olennikov, L. Tankhaeva, Chem. Plant Raw Mater., 4, 29-33 (2006)

12. A. Podkorytov, I. Kadnikova, Quality, safety and methods of analysis of aquatic products, Guide to modern research methods of seaweed, herbs and products of their processing, 3, (VNIRO Publishing House, Moscow, 2009)

13. K. Petrov, Workshop on the biochemistry of edible plant materials, (Food Industry, Moscow, 1965)

14. A. Zubchenko, Physical and chemical foundations of confectionery technology, Voronezh, State Technological Academia (2001) 